\section{Smoking cessation in diabetics: Need of the hour}

Sir,

Through this letter, I would like to draw attention of the readers towards a very important lacuna in diabetes management i.e., smoking cessation. Although much emphasis is given on educating the diabetic patients about the importance of exercise, diet control and timely drug therapy, but the issue of importance of smoking cessation remains relatively unaddressed.

Smoking in India has been prohibited in public since $2^{\text {nd }}$ October 2008 under Prohibition of Smoking in Public Places Rules, 2008. Many districts in Haryana have imposed a ban on hookah smoking as well. ${ }^{[1,2]}$ But sadly, even these laws have not been able to change the scenario much. Smoking is still widely prevalent in the society. According to a World Bank Report in 2009, 26.25\% of males and $3.64 \%$ of females in India smoke tobacco in one or the other form such as bidis, cigarettes, cigars, hookah or chillum. Another dark side of the scenario is that the smoking prevalence in women has even increased when compared with previous years. ${ }^{[3,4]}$

Smoking not only provokes the onset of diabetes in normal subjects by causing deterioration of glucose metabolism, but also worsens type 2 diabetes by causing greater insulin resistance, impaired beta-cell function, less insulin secretion and chronic inflammation. It aggravates the macro- or micro-vascular complications of diabetes such as nephropathy, neuropathy and coronary artery disease. ${ }^{[5,6]}$

Thus, there is a pressing need to spread awareness among the public and especially the diabetic individuals regarding the importance of smoking cessation. It is the duty of health-care providers to advise the diabetic patients about the benefits of stopping smoking and the options available, which can help them to quit the habit. In nutshell, smoking cessation programs should be made an integral part of diabetes management. Without this, diabetes care is largely incomplete.

Garima Bhutani, Prem Verma Department of Pharmacology, BPS GMC for Women, Khanpur Kalan, Sonepat, Haryana, India

\section{REFERENCES}

1. “Hookah bars banned in Gurgaon”. Hindustan Times. 2012 Apr 04. [Last retrieved on 2013 Aug 13].

2. "Hookah bars banned in Panchkula". The Hindu. 2011 Dec 01. [Last retrieved on 2013 Aug 13].

3. Smoking prevalence; females (\% of adults) in India. Available from: http://www.tradingeconomics.com/india/smokingprevalence-females-percent-of-adults-wb-data.html. [Last cited on 2013 Aug 12].

4. Smoking prevalence; males (\% of adults) in India. Available from: http://www.tradingeconomics.com/india/smokingprevalence-males-percent-of-adults-wb-data.html. [Last cited on 2013 Aug 12].

5. Fagard $\mathrm{RH}$, Nilsson PM. Smoking and diabetes - The double health hazard! Prim Care Diabetes 2009;3:205-9.

6. Obert DM, Hua P, Pilkerton ME, Feng W, Jaimes EA. Environmental tobacco smoke furthers progression of diabetic nephropathy. Am J Med Sci 2011;341:126-30.

\begin{tabular}{|l|l|}
\hline \multicolumn{2}{|c|}{ Access this article online } \\
\hline Quick Response Code: & Website: \\
\hline & www.joshd.net \\
\hline & \\
\hline
\end{tabular}

